Portland State University

PDXScholar

$10-1-2001$

\title{
Transgenic Crops and the Environment: Missing Markets and Public Roles
}

David E. Ervin

Portland State University

Sandra S. Batie

Michigan State University

Follow this and additional works at: https://pdxscholar.library.pdx.edu/econ_fac

Part of the Agricultural and Resource Economics Commons, and the Public Economics Commons Let us know how access to this document benefits you.

Citation Details

Batie, S. S., and Ervin, D. E. (2001). Transgenic Crops and the Environment: Missing Markets and Public Roles. Environment And Development Economics, 6(4), 435-457.

This Article is brought to you for free and open access. It has been accepted for inclusion in Economics Faculty Publications and Presentations by an authorized administrator of PDXScholar. Please contact us if we can make this document more accessible: pdxscholar@pdx.edu. 


\title{
Transgenic crops and the environment: missing markets and public roles
}

\author{
SANDRA S. BATIE \\ Elton R. Smith Professor in Food and Agricultural Policy, Department of \\ Agricultural Economics, Michigan State University, East Lansing, \\ Michigan 48824 \\ DAVID E. ERVIN \\ Senior Policy Analyst, Henry A. Wallace Institute, and Research Professor, \\ Environmental Science, Portland University, Portland, Oregon 97207
}

\begin{abstract}
The rapidity of change has left scant opportunity for investigation of the consequences of adoption of transgenic crops on long-term ecosystem or economic system functioning. Economic theory suggests that, if the "Biotechnology Revolution" is left to market forces alone, there will be neglected public goods. Theory and limited empirical evidence suggests that there are significant incentives for private firms to discount and neglect certain environmental impacts and to develop products that meet mainly the needs of those able and willing to pay. Negative distributional impacts on rural societies and economies will not normally enter the private calculus nor will the long-term problems of insect and plant resistance. Thus, there is a strong case for enhanced public roles with respect to the use of transgenic crops. The adoption of the precautionary approach in public policies addressing transgenic crops is one alternative to better reflect public concerns.
\end{abstract}

Agricultural biotechnology has been described as a tsunami washing over agriculture - with fundamental impacts on how we grow and market our food and fiber. While some argue that current biotechnology innovations are just the next step in a long history of plant and animal breeding, others strongly disagree. Modern transgenic biotechnology involves genetic manipulations of transferring DNA from one species to another. For many, these unique attributes of transgenic plants are cause for concern, particular with respect to possible environmental impacts. This concern is heightened because of the large geographic distribution of such plants estimated to be 100 million acres in 1999 (James, 1999). Identifying these environmental concerns and assessing their validity is hampered by an exceptionally small core of scientific information (Ervin et al., 2001). Therefore, neither producers nor consumers can know the long-run environmental implications for any decisions they are making with respect to the use of transgenic crops.

An earlier version of this paper was presented at a Conference on Agro-industrialization, Globalization and Economic Development, 6-7 August, 1999, American Agricultural Economics Association Meetings, Nashville, Tennessee. 
In addition, the basic economic incentives faced by public and private actors can result in the exclusion or only partial inclusion of important public goods, such as the protection of the environment. Intellectual property rights temporarily protect transgenic crops and their products from competition and can lead to short-term monopoly rents for patent holders. Therefore, most private investors are interested in rapid pursuit of market share for profitable, low-exclusion cost goods. ${ }^{1}$ For them, desirable regulations tend to be those that will shorten the time between product development and market sales.

Regulators are not immune to the pressures from industry for speedy approval of release of transgenic seeds. Furthermore, if the private sector is to be the innovator of biotechnology advances, agencies must strike a balance between facilitating markets, protecting the public interest against uncertain risks, and exploiting the full potential of transgenic crops for public benefit. Because of the difficulties of managing these disparate incentives, particularly with an incomplete information base, a disconnect between social net benefits and private net benefits can arise. This disconnect provides a strong argument for a strong public role with respect to transgenic crops.

These issues can be explored within the framework of three themes. First, transgenic crops have a high potential for social good - literally improving the lives of billions of people. However, the development of such biotechnology has largely been a 'technology push' revolution, made possible through the rapid commercialization of recent scientific advances. Because the current biotechnology path is shaped mostly by private firms and less by public investment or regulation, because it is not guided by rising scarcity value for key environmental resources, such as water resources, nor pulled along by robust consumer markets, there is a particular need for careful public scrutiny. These missing incentives may mean that the social decision calculus for biotechnology is not well informed by the full range and distribution of benefits and costs.

The second theme is that missing markets for environmental and other attributes, as well as incomplete regulatory frameworks, may hinder transgenic crop biotechnology from reaching its potential for social good because important social costs are not reflected in the prices of inputs or outputs.

The third theme explores whether biotechnology is necessary for the protection of wildlife habitat and wilderness and to feed the world's population. While some claim that biotechnology is the answer to both food security and a healthy planet, other demur. The insights gained from examining these three themes can be used to draw public policy recommendations.

${ }^{1}$ Low exclusion goods are goods which are relatively easy to 'privatize'; that is, there are low transaction costs to exclude any potential user from access to the good. In contrast, high exclusion goods are characterized by high costs to exclusion. 
The environmental promise of transgenic crop biotechnology

There are at least four areas of potential transgenic crop contributions (Ervin, 1999; US Congress, 1993):

- gains in yields through improvements in plant efficiencies,

- lower costs of labor and agriculture inputs (including irrigation water),

- higher-quality food and value-added products, and

- environmentally benign methods of managing weeds and insect pests, and/or increasing yields.

Many of these potential contributions are environmental. For example, the new transgenic crops could reduce the use of chemical pesticides and lower the environmental risks of pesticides still in use. There may also be savings in energy and air emissions from more efficient transport of less perishable products. If drought resistant transgenic plants become a reality, not only could yield losses be minimized, but irrigation water could be reduced allowing for better protection of environmental values, such as adequate in-stream flows (e.g., fish habitat). Also, if transgenic crops translate into higher yields, there might be a reduction in the amount of grassland or forest land converted into agricultural production - with attendant environmental benefits. While the potential for these environmental benefits from transgenic crops is real, it is as yet unrealized.

Crop biotechnology is clearly in its infancy - emphasizing first generation input traits, such as herbicide resistance. The next wave of output quality traits is on the horizon (Kalaitzandonakes and Maltsbarger, 1998). While environmental benefits may be forthcoming from both of these generations of products, there is little research, or empirical evidence to date as to whether such benefits are significant. In addition, there are concerns that unintended negative environmental impacts will emerge and accumulate, and that potential public environmental goods will not be fully exploited. These concerns have been heightened not only by the rapid pace of product innovation, but also by recognition that the biotechnology crops are possible because of the existence of a new technology, one with which the world has little experience.

\section{Theme one: biotechnology as a technology-push revolution}

The greatest growth in transgenic products has been in crops with 'builtin' protection from pests, such as Bacillus thuringiensis (Bt), or those that are herbicide tolerant. ${ }^{2}$ The planting of both types of seeds has been extraordinarily rapid - from the early 1990s when there was none to the current 100 million acres (40 million hectares) (James, 1999).

The ability to move cells and the information embedded in them - from one plant or animal to another - has preceded a market demand for the

\footnotetext{
${ }^{2}$ Insect resistance is achieved with Bt crops - mainly corn and cotton - when the Bt insecticidal toxin is expressed by all the cells of the plant, thereby killing pests that feed on the leaves and presumably reducing the need to use certain conventional pesticides (Pretty, 1999). Herbicide tolerance in crops such as soybeans, canola, and sugar beets, allows for application of broad spectrum herbicides to the desired crop without damage, but with the suppression of weeds (Pretty, 1999).
} 
resultant products. Some authors therefore refer to crop biotechnology products as 'technology-push' (as opposed to demand-pull) innovations (Krimsky and Wrubel, 1996; Russell, 1991; Hackings, 1986). In Hicksian terms, biotechnology is an 'autonomous' rather than an 'induced' innovation; that is, biotechnology is a 'technology in search of applications' (Hackings, 1986: 2). For the private commercial sector, this search translates into a search for applications that can be patented and from which rents can be appropriated. The autonomous technology must ultimately be accepted by buyers, but its initial path may vary from a similar innovation spawned by rising prices of key inputs (e.g., management) and rising values of public environmental resources.

Consider, for example, herbicide resistant plants such as 'Round-up Ready ${ }^{\circledR \prime}$ soybeans. There are numerous alternatives to such herbicide resistant varieties as a means of managing weeds. As one critic notes:

Ridge tillage, no-till, banding, improved cultivars, newly registered post-emergent herbicides and new planting systems gave farmers many new options [for weed management]. The chemical toolbox is overflowing - more than a dozen new active ingredients have been registered in several families of chemistries. (Benbrook, 1999: 10)

Urgent demand for improved weed management does not, therefore, appear to be the main motivator for the development of 'Round-up Ready ${ }^{\circledR \prime}$ soybeans. Rather, biotechnology, as a method, provided Monsanto a way to protect the profits from their highly successful herbicide, Round-up ${ }^{\circledR}$, after Monsanto's patent expires in 2000, while giving farmers a way to lower their weed management costs. A unique business opportunity could be captured by developing 'packages' where newly patented herbicide resistant seeds are first linked with specific chemicals, then sold with a technology fee (Just and Hueth, 1993; Hubbell and Welsh, 1998; Benbrook, 1999). ${ }^{3}$

Because of the manner in which the products are regulated in the US, this biotechnology approach is particularly attractive to companies. In the US, the time required to approve a new biotechnology product is about one-half the time of approving a new chemical pesticide compound. The cost to approval for the biotechnology product is only one-fifth to oneseventh that of a chemical (Ollinger and Fernandez-Cornejo, 1995).

Such speed is particularly attractive to private firms because - as an autonomous innovation - the profitable sale of transgenic crops may involve considerable costs to market creation, in addition to large research and development costs. Clear, enforceable intellectual property rights and rapid development-to-market elapsed times are important factors for capturing monopoly rents from the use of transgenic crops.

The differences between these autonomous innovations and induced innovations technology suggest a hypothesis worthy of further exploration. The working hypothesis is: technologies that are pulled along by

\footnotetext{
${ }^{3}$ Obtaining the intellectual property rights for certain germplasm also better positions companies to profit from the second generation of agricultural biotechnology products - output quality traits.
} 
consumer demand, or by producer demand to lower environmental costs, are more likely to be guided by full social values, provided by either markets or extra-market (e.g., regulatory) institutions, than the 'technology-push' variety. Autonomous innovations arise largely in response to scientific advances. Only after they enter the market can consumers and producers express their preferences (i.e., provided feedback) and shape their development trajectory through market and extra-market signals.

Also, because autonomous, directed innovations tend to emerge from private laboratories with little contact with farmers or consumers, there may be less sensitivity to farming and eating as part of ecological and cultural systems. Thus, important factors underlying the social desirability of the product may be neglected (Busch et al., 1991).

The possibility that social goods may be neglected by autonomous innovations is heightened by the dominance of the private sector in the biotechnology arena. It is more likely that autonomous innovations that arise primarily from the private sector, such as biotechnology, will catch public regulatory bodies unprepared for unintended social consequences. Furthermore, the firms' need for early product arrival into markets, means firm's may put considerable pressure on the regulatory institutions to respond quickly. Lengthy regulatory steps to determine possible, but uncertain, long-term environmental impacts may threaten the profitability of large private investments. Yet, unless forced by a regulatory requirement, existing incentives are for the private sector to neglect public goods, such as protection of surface water or preservation of wildlife (Batie and Ervin, 1999).

In the US, the widespread and rapid adoption of herbicide-resistant soybeans or Bt corn and cotton suggests that many farmers believe the new transgenic pest management features are worth their cost. However, refusals of European and Japanese consumers as well as some US firms (e.g., Gerber and Heinz) to purchase products containing transgenic plants suggests that at least some consumers are not yet convinced that there are net benefits for them from the products.

\section{Theme two: missing information and missing markets}

The 'Biotechnology Revolution' is being criticized for ignoring or exacerbating environmental problems. The 'under supply' of environmental benefits or the 'over supply' of environmental costs ${ }^{4}$ of transgenic crops are classic examples of 'missing markets', where the normal workings of a private market exclude full consideration of important outcomes off the farm and in the future. The potential environmental benefits of first generation products relate to whether there is an actual reduction of use in the more toxic pesticides due to the adoption of herbicide resistant or Bt crop seeds (as compared to conventional crops.) The potential environmental costs relate to whether transgenic crops can harm the environment

\footnotetext{
${ }^{4}$ For the purposes of this paper, we are not addressing possible food safety issues such as possible toxic or allergenic effects from inserted genes, from non-food genes inserted in foods, antibiotic resistance or from unintended expression of other plant traits due to insertion of new genes (The Royal Society, 1998).
} 
through negative impacts on non-target species or bio-diversity, on pest or virus resistance, and on transfer of genes to wild relatives or to conventional crops (The Royal Society, 1998).

While environmental problems can emanate from conventional crops, concern with transgenic crops is heightened because of the novelty of the traits (e.g., tolerance to cold obtained from other species' genes), because other components of the ecosystem have not coevolved with these traits, and because of the possible amount of acreage dedicated to such crops. Furthermore, because the private benefits of transgenic crops will occur sooner and to a more focused set of beneficiaries than will any unintended environmental costs, there can be a discounting of those costs by both private companies and regulatory institutions (Batie and Schweikhardt, 1995). The same could be said for some non-transgenic conventional products and practices. However, the rapid development and adoption of transgenics as well as the nature of the technology that produced them, add a particular urgency for analysis that is unique to these products.

Such analysis is challenging; not only does each transgenic crop pose its own potential benefit, it also poses its own unique environmental risk (Pretty, 1999). Differentiating between types of products and/or technologies is essential for analysis. However, there is not yet a strong, credible scientific information base with which to address many of these concerns. The paucity of such information is exacerbated by the reluctance of private companies to share information on their products, since such information is a crucial component determining return on their investments in transgenics. What follows then is a brief sketch of these concerns, not a definitive, research-based determination of their validity.

Transgenic plants and the environment ${ }^{5}$

The concerns surrounding potential negative environmental outcomes of transgenic crops include impacts stemming from changes in pesticide use, impacts on non-target species, and pest and virus resistance.

Pesticide use impacts An environmental question with respect to genetically engineered crops is whether they will be able to provide more environmentally benign methods of managing weeds and insect pests, as promised. Unfortunately, an accurate assessment of the contribution of herbicide-tolerant or $B t$ crops either to environmental improvements or to producer profits will require a decade or more of actual field use (Gianessi and Carpenter, 1999). This long evaluation period is necessitated by the variability in weather, market prices, and pest infestation across regions and time.

Because of changes in types and severity of pest infestations and hence chemical use, the overall impact on the environment from agro-chemical use following the adoption of transgenics depends on the toxicity of and exposure to the chemicals used compared with the pre-transgenic chemical portfolio. Preliminary evidence from the few years of experience with transgenic crops in the US, as well as evidence from field experi-

\footnotetext{
${ }^{5}$ An expanded version of this section is contained in Ervin et al., 2001.
} 
ments, suggests that changes in pesticide use rates have been variable (Gianessi and Carpenter, 1999). For example, recent USDA studies (USDA, 1999a and 1999b) found that, in the aggregate, as more US farmers adopted transgenic crops, insecticidal treatments have been reduced on corn (USDA, 1999a); whereas, the use of glyphosate herbicides, such as Roundup $^{\circledR}$, on corn and soybeans has increased. ${ }^{6}$ However, other, more toxic, chemical decreased in use. The situation varies by crop and by region. For example, when US cotton farmers adopted Bt cotton in the Southeast, the results were less clear, because cotton has so many pests. In some cases, there were more pesticide applications on $B t$ cotton than before adoption - because the number of pests not susceptible to $B t$ increased following the adoption of Bt cotton (USDA, 1999a). The introduction of genetically transformed potato plants did not have a major impact on insecticide use. Such variable outcomes could be the result of early adoption problems or the severity of pest problems and may not be representative of results over longer periods of time.

There may also be other types of environmental impacts. For example, herbicide-resistant plants may also allow reductions in plowing (as opposed to conventional chemical applications) and thus reduce wind and water sediment damages. However, at least to date, there is not enough evidence to conclude whether overall and long-run pesticide damages to the environment are reduced due to the adoption of biotechnology products. If early insect and weed resistance develops, the long-run use of chemicals use with transgenics should exceed the short-run levels.

Non-target species impacts Although nearly half of the US' major crop acreage is in transgenic crops, there has not been an independent assessment of whether certain species are benefiting or being harmed by the transgenics. Many crops are habitat to a range of insects or predatory arthropods that prey on unwanted insect pests, that provide food for birds, and that pollinate plants. These insects are referred to as 'beneficials' as integrated pest management strategies. Bt toxins can harm both pests and 'beneficials' - although so can conventional insecticides. There is a laboratory research result that $B t$ transgenic plants pollen kills non-target Monarch butterfly larvae, if the larvae are exposed to Bt pollen (Losey, Rayor, and Carter, 1999). Whether wild Monarchs - whose larvae prefer to eat milkweed and not corn - will actually be killed in significant numbers by $B t$ crops, however, is not yet resolved. ${ }^{7}$ For another example, no harm has been shown to come to bees from Bt toxins (The Royal Society, 1998).

\footnotetext{
${ }^{6}$ Yields results have been quite variable with some crop/region combinations not seeing yield differences and some with spectacular yield results. While herbicide resistance soybeans appear to have a yield drag, in some US Midwest regions, farmers planting $B t$ corn had yields 26 per cent higher than conventional, nonmodified crops (USDA, 1999a). Even where there is a yield drag, farmers are reporting savings in labor costs from weed control that continue to make planting of transgenic crops profitable.

7 To be meaningful, the comparison should be the number of Monarch butterflies killed with the transgenics compared to the number killed without the transgenics, but with the use of conventional pesticides.
} 
However, Hilbeck et al. (1998) found that 62 per cent of the lacewing larvae (predators of many agricultural insect pests) died after consuming prey fed with Bt corn (versus 37 per cent mortality for the controls). ${ }^{8}$

$B t$ is only the first generation of built-in plant toxin; patents have already been secured on genes for toxins from scorpions, cone snails, funnel spiders, and wasps (Pretty, 1999). The impact of the successful expression of these genes on non-target species appears to be unknown. Other concerns include whether there could be a disruption of soil ecological functioning from the breakdown of crop tissue (Saxena, Flores, and Stutzky, 1999; Waltrud and Seidler, 1998) and release of toxins or if sequestration of toxins by herbivores could have unintended secondary effects on their predators (Pretty, 1999) or the herbivores (e.g., cattle) themselves.

A fundamental concern with respect to biotechnological impacts transcends the potential unintended impact on any single species. It relates to whether the reduction in diversity of crop and wild plant and animal species creates a more fragile, less sustainable agricultural system (Hubbell and Welsh, 1998; Hassebrook, 1989). Such narrowing of diversity - particularly in situ cropping systems - has been happening for sometime, but could be accelerated by adoption of transgenic crops (The Royal Society, 1998; NRC, 1993). (There is, however, protection of genetic diversity in $e x$ situ seed banks.) The concern is that the very uniformity demanded and rewarded by the emerging food system creates greater environmental risks for biological damage or system collapse.

Another broad ecosystem concern is the potential effects of introducing multiple transgenic crops. A strong conclusion in the 1998 Royal Society Statement is the need for evaluating the environmental effects of transgenic crops as a whole, in addition to the case-by-case regulatory reviews. That is, an individual crop approach will not likely capture the full set of long-term continued effects of transgenic crops on whole ecosystems, whether positive or negative. Moreover, the case-by-case analysis will miss possible interaction (synergistic) and scale effects. This error may occur, for example, if different transgenic crops exert common environmental influences. Individual reviews will also miss threshold issues that may occur if common environmental effects of transgenic crops are aggregated across the countryside (e.g., predator-prey relationships) (Ervin, 1999).

Pest and virus resistance Another environmental concern is that transgenic plants will either become weeds themselves or will transfer pollen to wild relatives that will become weeds (Hubbell and Welsh, 1998; Linder and Schmidt, 1995; Hails, 2000; NRC, 2000; Snow and Palma, 1997; Rissler and

\footnotetext{
${ }^{8}$ There is non-crop research suggesting unintended negative consequences on nontarget species from release of transgenic organisms. A recent study at Purdue University found that transgenic salmon or tilapia could present a significant threat to native, wild species. Dr Bill Muir, a geneticist, found that transgenic fish have an advantage in attracting mates, but their offspring have lower survival rates. Muir concludes 'a transgenic animal could bring a wild population to extinction in 40 generations' (Sigurdson, 2000: 6). Muir refers to this gene as a 'trojan horse gene'.
} 
Mellon, 1996; Krimsky and Wrubel, 1996; The Royal Society, 1998). If these weeds have particular fitness advantages, such as being herbicide-resistant, they may become extremely difficult to control in agricultural settings. ${ }^{9}$ Thus, in regions where plants have weedy relatives, resistant weeds may pose a threat and may out-compete native plants. Such competition could alter the current eco-system of a region and/or threaten wild crop gene pools.

While gene flow that enhances weediness can and has occurred with conventional crops, some scientists agree that crop-to-wild outcrossing will become more common with transgenic crops (Snow and Palma, 1997; NRC, 2000). There are numerous cases where 'exotics' (e.g., harmful, nonindigenous species) associated with agriculture have caused problems and where genetic diversity has been diminished by the introduction of crops (NRC, 1993; Rissler and Mellon, 1996; US Congress, OTA, 1993).

Similar concerns relate to the possibility of intensifying existing or creating new viruses (Rissler and Mellon, 1996). Viral epidemics from natural recombinations have already occurred. For example, the African cassava mosaic virus is just such an epidemic (Conway, 1999).

An additional concern addresses organic agriculture. Should key pests develop resistance to $B t$, organic growers will have lost a major pest control too. ${ }^{10}$ Susceptible insects can be thought of as an open access resource. Economic theory suggests that if the benefits of drawing on this stock of susceptibility is high enough, the stock will be drawn down too fast from a social accounting perspective (Clark and Carlson, 1990; Barnett and Gibson, 1999). The ultimate impact on the environment of insecticidetolerant insects could be negative, as organic farmers resort to other insect control chemicals and practices.

One approach to managing pest resistance has been to require farmers using $B t$ crops to plant refuges with non $B t$ crops. The intention is to dilute the frequency of recessive resistant traits in the population of target insects (Barnett and Gibson, 1999; Hargrove, 1999). Unfortunately, there is limited scientific information to date on how to best design a refuge to protect $B t$ susceptible genes. Furthermore, for any farmer, there is little incentive to invest in protecting the open-access resource - the potential to 'free ride' on the efforts of others is high (Barnett and Gibson, 1999; Hargrove, 1999). Because of these concerns, it is unknown whether a refuge will be adequate to avert or delay pest resistance.

A more fundamental criticism of the biotechnological approach to pest control is that it continues along the path of providing a single control component per pest and thus encourages dependence on pesticides (Hubbell and Welsh, 1998). Not only does such a path assure that there will be an increase in pests that are resistant (Hubbell and Welsh, 1998;

\footnotetext{
${ }^{9}$ Furthermore, if farmers have to resort to pre-emergent herbicides, they may negate the benefits from the planting of herbicide tolerant plants (Hubbell and Welsh, 1998).

${ }^{10}$ Dr Bruce Tabashnik, Head of Entomology at the University of Arizona, notes that there is evidence of $B t$ resistance for several insects in the US, Central America, and Asia (Hargrove, 1999).
} 
Hassebrook, 1989; Rissler and Mellor, 1996), such a path also diverts attention from whole system management techniques, which are undergirded with understanding of ecological connections (Krimsky and Wrubel, 1996)d. Thus, the critics worry that without more public investment, there will be less research and development into non-pesticide alternatives, such as reintroduction of pest-controlling crop rotations, biological controls, cover crops, or intercropping (Cramer et al., 1991; Liebman and Jancke, 1990). This criticism is not unique to transgenic plants, however. It is the same criticism leveled at the agricultural system since it became chemically dependent.

An alternative, less chemical dependent path could be supported by different biotechnology products than those that are currently emerging. Many argue that the alternative path is more socially desirable and can be yield enhancing (Pretty, 1999). But it is a path that requires a reorientation of agricultural research in ways that embed the lessons of evolutionary biology (Altieri, 2000; Benbrook, 1999). However, it is difficult to capture the full social benefits as profits from many of these alternatives, thus they tend to be neglected by the private sector.

Theme three: transgenic crops and habitat conservation

An issue related to the environment pertains to whether transgenic crops will result in less need for cultivated land, and therefore result in a more natural habitat (Avery, 1994; Shapiro, 1999). This issue usually is framed as the need to feed a hungry world while protecting the environment. Such a framing of the issue subsumes several assumptions:

1 that people are or will be hungry because of low agricultural yields and higher costs of food,

2 transgenic crops are necessary to adequately raise yields and lower costs of food, and

3 as society meets food needs with expanded acreage devoted to agriculture, more natural habitat will be lost - unless there are offsetting higher yields on existing cropland acreage. ${ }^{11}$

Like many arguments about biotechnology, this one appears to be oversimplified.

\section{Feeding the poor}

The first assumption is that people are hungry because of low agricultural yields and higher costs of food. However, it is well known that, at least on the global scale, people are not hungry because of insufficient agricultural yields. Rather, people are hungry because they are poor (Serageldin, 1999; Conway, 1997). Consider the Green Revolution, ${ }^{12}$ which was motivated by

11 There is an additional assumption embedded in this argument: once a nation's agricultural needs are met, cultivated land will be returned to wild habitat (Pretty, Vorley, and Keeney, 1998).

12 The Green Revolution was primarily driven by public investments in plant breeding (Conway, 1997). Starting as early as the 1960s, plant breeders in international centers were applying modern research techniques to the agricultural 
public concerns to feed a hungry world. The fertilizer-responsive, dwarf plants that resulted meant that overall food production of major cereal crops doubled or even tripled in some regions (Lipton and Longhurst, 1989). Despite such successes, the extent to which the poor actually benefited from the 'Green Revolution' has been the subject of much debate (Conway, 1997; Lipton and Longhurst, 1989; Hazell and Ramasamy, 1991). In many countries, the major benefits of new varieties accrued to the landowner elites and urban consumers, but not the rural laborers. Indeed, in some cases, it appears that falling labor wages and rising land rents offset the gains from falling food prices (Lipton and Longhurst, 1989). The urban poor have benefited most whenever government policies ensured that increased yields translated into lower domestic prices (Conway, 1997). Despite the uneven incidence of the benefits of the Green Revolution, the aggregate percentage of the developing world population who are not getting enough to eat has declined from 50 per cent 35 years ago to about 20 per cent today (Conway, 1997). These successes were due in part to exceptionally impressive increases in global productivity but also, in part, to the existence of the appropriate institutional settings to lower the access cost of food for the poor. Despite these successes, however, the absolute numbers of undernourished people have declined by only 80 million (from 920 million to 840 million) between 1960 and 1990 (McCalla and Brown, 1999).

Thus, a close examination shows that the ultimate impact of the 'Green Revolution' on the poor has depended on the geographic, social, and political circumstances and has been quite uneven across the globe (Conway, 1997). While the 'Green Revolution's' high-yielding varieties were potentially poverty alleviating, a broader context of appropriate nondistortionary agricultural, rural development, and economic policies was needed to capture this potential. The lesson is that until the problem of food access for the population who lie outside of the market is resolved, growing more transgenic corn, soybeans, or wheat by itself will do little to feed the world's hungry (Benbrook, 1999).

Yield increases and transgenic crops

The second assumption in the transgenics-save-habitat argument is that transgenic crops are necessary to raise yields. While there is not a direct relationships between increased world crop yields and food security for the poor, fewer acres have been devoted to agricultural purposes than if yield increases had not occurred. Without continual agricultural yield improvements, many more millions of acres will have to be devoted to agricultural uses as world population grows and as incomes and diets

problems of the developing world. Since then, plant breeders of the International Agricultural Research Centers (IARC's) supported by the Consultative Group on International Research (CGIAR), as well as National Agricultural Research Systems (NARS), have developed modern varieties of plants to be grown in a wide variety of conditions in the less developed world. There are now sixteen IARC's grouped under the CGIAR. 
improve (Shapiro, 1999; Conway, 1997). However, the question remains whether transgenic crops are the only or best way to achieve these yield increases.

Some assert biotechnology is the solution to achieving a high yield, environmentally protecting agriculture (Shapiro, 1999); others suggest it should be considered an essential partner with more ecological approaches, such as integrated pest management and with improved economic policies (Conway, 1999). Still others contest whether transgenic crops are necessary to achieve yield advances. For many reasons, many farmers around the world are not near the potential of their land, using either conventional or (non-biotechnological) alternative practices (Ruttan, 1999; Pretty, 1999). Furthermore, new agroecology methods of production can also increase yields (Altieri, 20000). Thus, some argue, and some studies (Pretty, 1999) suggest, that transgenic crops are only one of a suite of possibilities for raising world food yields. From a farmer's perspective, whether transgenic crops are a superior alternative to, say, using more inputs, will depend on the relative prices of inputs and the price received for the crops as well as his or her budget constraint. From a social perspective, whether transgenic crops are a superior alternative will depend on a full social accounting - including the potential costs from unintended negative consequences.

Finally, some doubt that adequate private investments are being made to break the physiological constraints that limit future increases in crop yields. Ruttan argues that current private investments in biotechnology favor input-saving technologies and the next generation of private investments will be focused on quality attributes. Thus 'it would appear exceedingly rash to predict that ... [there will be] any measurable impact on production in the next several decades' (Ruttan, 1999 referencing Duvick, 1996). McCalla and Brown (1999) also note that 90 per cent of the world's food consumption takes place in the country where the food is produced. Critical food needs are in the Tropics, but these are not the locations with expected high private returns due to transgenic innovations.

Since the 'biotechnology revolution' is being led by private companies, there is little reason to believe the products that emerge are destined to feed the billions on the planet or to protect the environment (Conway, 1997). Because the private sector is motivated by incentives such as profits, timely return to stockholders, and market share, it is not surprising that the genetic manipulation funded by the private sector would emphasize investments and product attributes that would differ from that of a more complete public agenda (Conway, 1997; Heffernan, 1999). Put more formally, one would expect the private sector to invest in low exclusion goods, such as seed-chemical-machinery 'packages' or value-added foods, and neglect high exclusion goods, such as protection of biodiversity or the improvement of minor traditional crops in the developing world. Private investments can thus be expected to focus on high-return and high-value crops, on labor-saving technologies, and the needs of capitalintensive farming in order to feed those who can pay, and not on the needs of the smallholder farmers in the developing world nor on 
environmental conservation (Conway, 1997) ${ }^{13}$ Thus, there is a role for the public sector.

Even with more public sector involvement, however, there may be barriers to more innovations directed at the needs of the poor. Even if barriers posed by the high cost of biotechnology research drops, public institutions may be unable to gain access to the information for, or the right to, create new products - such as customized seeds for micro-climates or transgenic crops that do not require pesticides (Conway, 1999). 'Public sector plant breeders. . . are handicapped by the high disparity in resources and negotiating power between themselves and the companies [who closely guard their proprietary technologies]' (Conway, 1999).

Yields and wildlife

The third assumption of the argument involves predicting the environmental outcomes expected with adoption of transgenic crops. The assumption is that high-yielding agriculture saves habitat. It is not obvious that high yields correlate well with acreage in wilderness and enhanced benefits for wildlife nor that low yields are necessarily detrimental to wildlife. Wildlife and agriculture, for example, are not necessary incompatible - farmland can support a broad diversity of wildlife as well as water quality and flood control benefits (Pretty, Vorley, and Keeney, 1998). And, whole expansion of agriculture into wilderness areas can occur because of high prices for commercially traded foods and fibers - perhaps as a result of low yields relative to quantities demanded - expansion can also occur as poor farmers pursue low-input extractive farming systems for a subsistence living. The latter motivation may have little to do with world yields or prices. Two studies of the Amazon forest, for example, found that intensifying existing cropland use did not remove the pressures for deforestation (Carpentier et al., forthcoming; Yanggen and Reardon, 2001). Such evidence suggests that high yields may be necessary to protect habitat in the aggregate, but that high yields are not sufficient to do so.

Furthermore, much of the land not cultivated is currently uneconomical to farm at today's prices - being too far from markets, being too poor or quality, and/or requiring irrigation or drainage (Conway, 1999). Which of these lands would be cultivated at higher prices is an unresolved empirical question. Put simply: the relationships between transgenic crops, cropland intensification, and habitat conservation is neither well researched nor clear. The argument that adoption of transgenic crops will either feed the poor or will save habitat oversimplifies exceptionally complex situations.

13 There are cases where private companies have partnered with public institutions or foundations to focus on the needs of poor people. For example, Monsanto has entered into agreements with both Kenyan and Mexican research institutions for the development of virus resistant crops (Serageldin, 1999). While these partnerships appear to be working well, they are few in number and modest components of philanthropic programs. And, many argue that public or foundation funding for biotechnology products geared to environmental protection or the needs of the poor are quite inadequate (Ruttan, 1999; Serageldin, 1999). 


\section{Policy implications}

The pace of transgenic crops advances and adoption have been so rapid that they are outstripping our knowledge and the capacity of our institutions. Complicating the situation is the lack of a credible, mature information base by which to evaluate net environmental benefits; empirical evidence is just beginning to emerge. While some of the biotechnology firms have information on biotechnology product performance, at least some of this information is guarded as intellectual property (Ransom, Busch, and Middendorf, 1998).

The outstripping of our science knowledge combined with missing markets implies that responsible regulatory agencies have little information to assess the long-term effects of transgenic crops, increasing the probability of a disconnect between net social and net private benefits. While the US federal government has protocols in place to evaluate biotechnologies for expected environmental, a unified approach across agencies, responsive to the missing markets discussed above, does not exist (NRC, 2000).

Elements of a precautionary approach

One possible response to this disconnect and uncertainty is for the US to adopt a precautionary approach. One way to conceptualize the precautionary approach is to consider who bears the risks of an error. There are essentially two types of errors: Type I and Type II. Type I, is accepting that significant risk will occur when, in fact, risks do not exist. Type II is the error of accepting that there is not environmental risk when, in fact, significant risks do exist. The proverbial version of avoiding a Type I error is 'he who hesitates, is lost'; whereas, that of avoiding a Type II error is 'better safe than sorry'. However, the changes of making each type of error are inversely related to each other. That is, regulatory systems that reduce one type of error will necessarily increase the chance of making the other type of error. The degree of confidence required by a regulatory system to avoid either type of error is clearly a crucial policy choice.

A precautionary approach essentially is one that reduces the chance of making a Type II error. However, the lower the probability of making a Type II error, the higher the costs (i.e., deferred benefits) stemming from delay. These costs will be borne by investors and others who would have benefited from the earlier or broader use of transgenic crops. The 'precautionary principle' is firmly embedded in much of European environmental policy, and requires that regulatory action be taken to protect the environment before resolving uncertainty about possible environmental or health damages (Hanley, Shogren, and White, 1997). In contrast to Europe, most US crop protection policy tends toward avoiding Type I errors, ${ }^{14}$ that is, erroneously accepting that significant risks will occur when in fact the

14 This crop protection approach can be contrasted with US pharmaceutical policy - where potential drugs must be proven both safe and effective before placed on the market. The drug policies are designed to avoid Type II errors. Recently the US Food Quality Protection Act (FQPA) also adopted the precautionary approach with respect to pesticide residues on food (Batie, Swinton, and Schulz, 1999). 
risks do not exist. For example, historically, much US legislation has given considerable weight to known pesticide use and requires a regulatory balancing against uncertain risks (Wargo, 1996). With this type of risk management and, assuming no countervailing liability rules for firms or farmers, most costs of being too aggressive in moving a crop from development to market (e.g., causing environmental harm) are borne by the general public. ${ }^{15}$

In considering the precautionary approach, the global cost of being cautious, needs to be balanced against the costs of being too aggressive. These costs are born by different publics. However, from social accountings of transgenic crops, a case can be made that the costs of caution generally should not be large. For example, Nelson et al. (1999) estimate only slight production benefits or price effects of full global adoption of $B t$ corn and Round-up Ready ${ }^{\circledR \prime}$ soybeans. For corn, the analysis projects only a 1.9 per cent increase in production and a 4.2 per cent decline in price; for soybeans, 0.5 per cent increase in production and a 0.6 per cent decline in price. Small benefits, if any, are estimated for farmers, and only negligible gains are expected for consumers. Moreover, a precautionary approach would not necessarily void those benefits, but delay them until more evidence is accumulated. Transgenic crop technology can come on stream rapidly after enough science has accumulated, and after adequate monitoring and reviews have been conducted, to assure that excessive environmental and other risks are not present. Furthermore, the precautionary approach avoids two different risks. One, the potential costs of not being precautionary are serious environmental effects, some that may be irreversible. Two, the loss of the technology is possible if larger damages or a strong public backlash prematurely stops development and diffusion.

In this latter case, designing precautionary regulatory institutions is not only in the interests of those concerned about negative environmental effects, but of the industry as well. If a large human or environmental health catastrophe emerges due to poor national or international oversight, it could not only cause a short-term setback for the industry, but also jeopardize the entire future of biotechnology and its considerable potential. In the US the nuclear power industry experienced this set of events and has never fully recovered.

A precautionary approach, however, does not imply a moratorium on all transgenic crops. Pretty (1999) and the Royal Society (1998) have made clear that this technology has very different strands, some for which we have good science with little apparent risk and others for which we have only meager understanding with large potential environmental effects. Thus, adopting a precautionary approach does not mean suspending development and diffusion of all products. If a product shows genuine productivity or other benefits, such as, economic, health, or environmental advantages, with little risk, it should be a prime candidate to move to practice. That judgment will depend on the particular country's economic, social, and environmental conditions, and cannot be generalized.

${ }^{15}$ However, one cost of being too aggressive that would be borne, at least in part, by producers would be increased pest resistance to chemical controls. 
The public role ${ }^{16}$

Whether the US moves toward a more precautionary approach, there appears to be a strong case to be made for an enhanced public role in the area of transgenic crops. The basic incentives, the missing markets, and the incomplete science all imply that the private sector will not by itself deliver the highest net social benefits. We envision the improved role for public institutions - along or in concert with others - to include two major elements.

1 Increase investment in public research and development for biotechnology to assure that the public good aspects of biotechnology receive adequate attention and to build a credible scientific base, including a comprehensive monitoring system, by which to evaluate biotechnologies and their impacts

Wise decisions about the development and diffusion of biotechnologies must begin with sound understandings of their productivity and economic, health, environmental, and social effects. Such a knowledge base is necessary, for informed decisions and for the importance of avoiding negative effects and capturing the full potential benefits of the technology. Furthermore, the growth of private funding, particularly when coupled with difficulties in access to certain germplasm because of patent laws can lead to neglect of research with high rates of social return, but with low rates of private profits. This neglected research includes basic research as well as research that addresses conservation and the environmental problems, alternative farming systems, rural development impacts, and nutrition and food access issues (Merrigan, 1999; Welsh, 1999).

While there is a small and growing core of knowledge about the environmental effects of transgenic crops, there are few incentives for private firms to add to this knowledge. For example, there is virtually no research that links the possible pesticide reductions and shifts in composition to environmental resources via fate, transport and toxicity. The lack of monitoring data of ecosystem scales is particularly noteworthy. An increase in public investment to acquire longitudinal data on shifts in pesticide use for adopters and non-adopters, and on factors that influence those shifts apart from adoption of crop biotechnology is crucial. In addition, it is essential to link the findings to spatial environment and resource conditions (Ervin et al., 2001).

There has also been insufficient research about the potential impacts of transgenic crops on non-target organisms (NRC, 2000). A larger systematic research program on the ecological implications of crop biotechnology, including wide-scale monitoring, is needed to anticipate the full range of environmental effects. In addition, it is important to make evaluations of transgenic insect-resistant crops relative to current agricultural practices (NRC, 2000). Chemically intensive practices potentially have more negative impacts on non-target organisms than certain transgenic insect resistant crops. However, the growing popularity of organic food and organic production systems points to the need to include alternative/sustainable systems in such comparative evaluations.

16 Expansions of this section are contained in Ervin et al. (2001). 
Similarly, our current knowledge is limited regarding the extent to which wild plant populations are affected by herbicides, insects, or viruses. Therefore, it is difficult to predict the extent to which wild or weedy populations would benefit from resistance to these factors (NRC, 2000). In general, transgene spread will occur. However, we do not know if transgenes will persist in the wild or increase the weediness of wild plants. The latter is more likely to happen if transgenic crops are introduced in areas close to their wild relatives.

Also, some promising research regarding genetic engineering of the chloroplast genome might result in genetic engineering methods that hobble transgene spread via pollen. In addition, incentives are needed to encourage firms to develop transgenic crops, recombinant technologies, and/or management regimes that would make outcrossing of beneficial genes to wild relatives less likely. Such incentives do not currently exist.

An increase in funding for risk assessment, including better monitoring systems, is a key policy need if the various resistance effects and their environmental impacts are to be understood. With improved monitoring and assessment information, the policy decisions on appropriate controls could be made with more precision. For example, the National Research Council (2000) criticized the US Environmental Protection Agency for not developing and implementing a general policy with respect to resistance management plans for transgenic crops. The Council goes on to recommend that resistance management regimes should be encouraged when 'a pest protectant or its functional equivalent is providing effective pest control, and if growing a new transgenic pest protected plant variety threatens the utility of existing uses of the pest protectant or its functional equivalent ...' (NRC, 2000: 103). ${ }^{17}$

In addition to reducing potential public costs, R\&D could also foster more public benefits. For example, future research on insect-resistant crops of all types, could investigate the development of traits which make resistance development less likely. Such traits could include manifestation of tolerance to pest damage rather than pesticidal properties (Hubbell and Welsh, 1998), or the ability to delay symptoms and damage from pathogens until after the plant has produced the valuable seeds or fruit. In this vein, the National Research Council recently cited the need for ecological research to develop pest-protected plants, including transgenic crops, which can be used within ecologically and evolutionary sustainable approaches to agriculture (NRC, 2000). A second example is the need to develop new crops with drought resistant characteristics. This emphasis seems particularly timely given the growing uncertainty of climate change and endangered species concerns that may limit agricultural uses of water. Institutions and incentives are needed to spur research in these areas, which will most likely originate in the public sector.

17 The Council intends for resistance management to apply to 'all uses' of the pest protectant, not just its use within transgenic crops. Regarding Bt crops and resistance management, this intention implies that resistance management practices would also be encouraged for microbial Bt sprays in addition to Bt crops. 
2. Develop appropriate regulatory frameworks for transgenic crops

Recommendations to improve the US regulatory system for agricultural biotechnology center on four areas of reform (Ervin et al., 2001). First, if environmental concerns are to be better addressed, the roles of ecological and other environmental scientists in the regulatory process should be increased. There is obvious synergy between this recommendation and one to increase public research on the public good aspects of agricultural biotechnology. Regal (1999) had proposed the wider use of multidisciplinary review teams, including environmental scientists. To help make the environmental scientists effective members of the process, the United States Department of Agriculture budget dedicated to risk assessment of transgenic crops would also need to be increased. Traditionally, the amount available for risk assessment is a mere $\$ 1$ million to $\$ 2$ million. Yet risk assessments are necessary to close the knowledge gap. Also, Hails (2000) argues that research should move from the laboratory and limited field experiments to large-scale trials. Such trials will account for the fact that large pollen sources can interact on a regional scale, increasing the risk of unintended environmental impacts.

Another possible improvement in the regulatory framework would be for an environmental agency to lead the ecological assessment of transgenic plants (Rissler and Mellon, 1996). Under such a reform, all transgenic crops would be tested before release (Krimsky and Wrubel, 1996), at least for the gene flow and 'weediness', using a three-tiered approach that would separate low- and high-risk crops early in the process (Rissler and Mellon, 1996). Designating a lead environmental body also may help eliminate potential gaps in regulatory coverage identified by the National Research Council (2000), and reduce the concern that the USDA is simultaneously advocating the use of transgenic plants while trying to regulate their environmental risks. Similarly, the lead agency could exercise oversight regarding 'revolving door' job switches among industry and government regulators (Regal, 1999).

A third recommendation is to improve the public transparency of the US regulatory process. The NRC review (2000) concluded that 'The quantity, quality, and public accessibility of information on the regulation of transgenic pest-protected plant products should be expanded' (NRC, 2000, p. 15). The USDA database was deemed particularly useful and recommended as a model. However, they recommended more readily available and clearer public data from the Environmental Protection Agency. A related issue is that biotechnology companies select the priority information for review, and thus the federal agencies may not be able to obtain adequate information to inform the public (NRC, 2000). This problem is compounded when the biotechnology companies guard much of their data as confidential business information.

In addition, the present regulatory system does not consider socio-economic factors - the so-called 'fourth criterion' - in the processes (Lacy, forthcoming). There is a strong public good argument for assuring an adequate margin of safety for determining whether transgenic plants should be released. The selection of Type I or Type II error and the confidence level is inherently a social decision not a scientific one. Such a reform 
could result in more public involvement in the decision process, and thereby bolster the public's confidence in transgenic plants. However, any public participation requirements would have to be designed carefully to control excessive transaction costs and to balance powerful lobbying groups that espouse narrow views.

Given the vast potential importance of the transgenic crops for food, energy, human health, and the environment, an independent over-arching body commissioned by the government may eventually be needed to evaluate the full sweep of issues emerging from the transgenic crops. The Royal Society Committee endorsed the creation of such a body in the United Kingdom. The US does not have such a body. Building such as institution in developing countries with little science infrastructure or regulatory apparatus would be a formidable challenge. The greatest challenge may be in creating an effective international institution empowered to govern the diffusion of biotechnologies that carry transboundary environmental risks. None exists at this point.

\section{Conclusion}

Transgenic crops clearly have significant potential to improve welfare. Many of the short-term benefits to firms and farmers are already evident, with possible benefits to consumers clearly in sight. Yet there may be serious long-term environmental costs not yet seen, and there may be uses of biotechnology for products and techniques for which there are significant social benefits but insufficient commercial profits. There is a strong case to be made for more effective public involvement in transgenic crop development and adoption - not to replace markets but to complement them - by both requiring more comprehensive testing and risk assessment and by research on alternative cropping systems that will not be undertaken by for-profit firms.

Such enhanced public research requires more funding either from the general treasury or from taxes or fees from firms. Currently, a consortium of biotechnology firms have organized a pro-biotech informational campaign through the Council for Biotechnology that has \$50 million earmarked for the first year of a three to five year campaign (Hillyer, 2000) - an amount that dwarfs the United States' Department of Agriculture's $\$ 1$ million or $\$ 2$ million for transgenic crops risk assessments. Whether biotech firms should bear the costs of their own regulation and/or the provision of public goods is a political decision. However, a case can be made that, if companies acknowledged the existence of uncertain risks and if the public were assured that potential environmental outcomes were given more effective scrutiny by public institutions, public acceptance of transgenic crops would be more likely than with a pro-biotech campaign (Sandman, 1999). Such is one of the lessons of the US nuclear power industry's history of inadequate risk communication.

\section{References}

Altieri, M.A. (2000), 'The ecological impacts of transgenic crops on Agroecosystem health', Ecosystem Health (March).

Avery, D. (1994), Saving the Plant with Pesticides and Plastic, Indianapolis, IN: Hudson Institute. 
Barnett, B.J. and B.O. Gibson (1999, September), 'Economic challenges of transgenic crops: the case of Bt cotton', Journal of Economic Issues, 33(3): 647-659.

Batie, S.S. and D.B. Schweikhardt (1995), 'Demosclerosis: implications for environmental and agricultural policy analysis', Journal of Agricultural Economics, 77: $1126-1127$.

Batie, S.S. and D.E. Ervin (1999), 'Flexible incentives for environmental management in agriculture: a typology', in C.F. Casey, A. Schmitz, S. Swinton, and D. Zilberman (eds.), Flexible Incentives for the Adoption of Environmental Technologies in Agriculture, Boston: Kluwer Academic Publishers, pp. 55-78.

Batie, S.S., Scott M. Swinton, and Mary A. Schulz (July 1999), 'FQPA implementation to reduce pesticides risks: Part I agricultural producer concerns', Staff paper 99-3, Department of Agricultural Economics, Michigan State University, East Lansing, Michigan.

Benbrook, C. (1999, January), 'World food system challenges and opportunities: GMOs, biodiversity and lessons from America's heartland', Paper presented at the University of Illinois World Food and Sustainable Agricultural Program, Champaign-Urbana, Illinois.

Busch, L. et al. (1991), 'Plants, Power and Profit: Social Economic and Ethical Consequences of the New Biotechnologies', Oxford: Blackwell.

Carpentier, C.L. et al. (forthcoming), 'Fale BEM: a farm level bioeconomic model for the western Amazonian forest margin', Discussion Paper, Environment and Production Technology Division, International Food Policy Research Institute, Washington, DC.

Clark, J.S. and G.A. Carlson (1990), 'Testing for common versus private property: the case of pesticide resistance', Journal of Environmental Economics and Management, 19: 45-60.

Conway, G. (1997), The Doubly Green Revolution: Food for All in The 21st century, Ithaca, NY: Cornell University Press.

Conway, G. (1999, 24 June), 'The Rockefeller Foundation and plant biotechnology', Invited Speech to Monsanto Company, St Louis, Missouri.

Cramer et al. (eds.) (1991), Controlling Weeds with Fewer Chemicals: The New Farm, Emmaus: Rodale Institute.

Duvick, D.N. (1996), 'Plant breeding: an evolutionary concept', Crop Science, 36: 359-548.

Ervin, D.E. (1999, 19 April), 'Agricultural biotechnology is a double-edged environmental sword', Henry A. Wallace Institute, Remarks to the National Association of Agricultural Journalists, Washington, DC.

Ervin, D.E., S.S. Batie, R. Welsh, C.L. Carpentier, J. Fern, N.J. Richman, and M.A. Schulz (2001), 'Transgenic crops: an environmental assessment', Policy Studies, No. 5, Henry A. Wallace Center at Winrock International, Washington, DC.

Ervin, D.E. and A. Schmitz (1996), 'A new era of environmental management in agriculture?', American Journal of Agricultural Economics, 78(5): 1198-1206.

Gianessi, L.P. and J.E. Carpenter (1999, July), 'Agricultural biotechnology: insect central benefits', Unpublished report, National Center for Food and Agricultural Policy, Washington, DC.

Hackings, A.J. (1986), Economic Aspects of Biotechnology: Cambridge Studies in Biotechnology 3, Cambridge: Cambridge University Press.

Hails, R.S. (2000), 'Genetically modified plants - the debate continues', Trends in Ecology and Evolution, 15(1): 14-18.

Hanley, N., J. Shogren, and B. White (1997), Environmental Economies: In Theory and Practice, New York: Oxford University Press.

Hargrove, T. (1999, January-February), 'Wrangling over refuge', American Scientist, 87: $24-25$. 
Hassebrook, C. (1989), 'Biotechnology, sustainable agriculture, and the family farm', in June Fessenden MacDonald (ed.), Biotechnology and Sustainable Agriculture: Policy Alternatives, National Agricultural Biotechnology Council Report No. 4. Ithaca, NY: Boyce Thompson Institute, pp. 38-47.

Hazell, P.B. and C. Ramasamy (1991), The Green Revolution Reconsidered: The Impact of High-Yielding Rice Varieties in South India, Baltimore, MD: Johns Hopkins University Press.

Heffernan, W.D. (1999, 6-8 June), 'Biotechnology and mature capitalism: feeding people or feeding firms', Paper presented at the 11th Annual Meeting of the National Biotechnology Council, Lincoln, Nebraska.

Hilbeck, A.M., M. Baumgartner, P.M. Fried, and F. Bigler (1998), 'Effects of transgenic Bacillus thuringiensis corn-fed prey on mortality and development of immature Chrysoperla carnia' (Neuropetera: Chrysopidae), Environmental Entomology, 27(2): 1-8.

Hillyer, G. (July 2000), 'Selling the benefits of biotech', Progressive Farmer (p. 29).

Hubbell, B.J. and R. Welsh (1998), 'Transgenic crops: engineering a more sustainable agriculture?', Agriculture and Human Values, 15: 43-56.

James, C. (1999), ‘Global review of commercialized transgenic crops 1999 Preview', ISAAA Brief 12.

Just, R.E. and D.L. Hueth (1993), 'Multimarket exploitation: the case of biotechnology and chemicals', American Journal of Agricultural Economics, 75: 936-945.

Kalaitzandonakes, Nicholas and Richard Maltsbarger (1998), 'Biotechnology and identify-preserved supply chains: a look at the future of crop production and marketing', Choices, 13(3): 15-18.

Krimsky, S. and R. Wrubel (1996), Agricultural Biotechnology and the Environment: Science, Policy and Social Issues, Urbana, IL: University of Illinois Press.

Lalcy, W.B. (forthcoming), 'Agricultural biotechnology, socioeconomic issues, and the fourth criterion', in T.H. Murray and M.J. Mehlman (eds.), The Encyclopedia of Ethical, Legal and Policy Issues in Biotechnology, New York: John Wiley \& Sons.

Liebman, M. and R.R. Jancke (1990), 'Sustainable weed managements', in C.A. Francis, C.G. Flora, and L.D. King (eds.), Sustainable Agriculture in Temperate Zones, New York: John Wiley, pp. 111-143.

Linder, C.R. and J. Schmitt (1995), 'Potential persistence of escaped transgenics: performance of transgenic, oil-modified brassica seeds and seedlings', Ecological Applications, 5: 1056-1068.

Lipton, M. and R. Longhurst (1989), New Seeds and Poor People, London: Unwin Hyman.

Losey, J., L. Rayor, and M. Carter (1999), 'Transgenic pollen harm monarch larvae', Nature (399): 214.

McCalla, A. and L.R. Brown (1999), 'Feeding the developing world in the next millennium: a question of science', Paper prepared for conference on 'Ensuring Food Security, Protecting the Environment, Reducing Poverty in Developing Countries: Can Biotechnology Help?', 21-22 October.

Merrigan, K. (1999), 'Needed patent reforms regulating biotechnology', The Environmental Forum, 16(2): 53-59.

NCR (National Research Council, Board on Agriculture) (1993), Managing Global Genetic Resources: Agricultural Crop Issues and Policies, Washington, DC: National Academy Press.

NRC (National Research Council, Board on Agriculture) (2000), Genetically Modified Pest-Protested Plants: Science and Regulation, Washington, DC: National Academy Press.

Ollinger, M. and J. Fernandez-Cornejo (1995, June), Regulation, innovation and market structure in the US Pesticide Industry, AER-719, Washington, DC: ERS, USDA. 
Pretty, J. (1999, July), 'Genetic modification of crops: partner or pariah for sustainable development', Paper prepared for The Biochemist [University of Essex].

Pretty, J., W. Vorley, and D. Keeney (1998), 'Pesticides in world agriculture: causes, consequences, and alternative courses', in William Vorley and Dennis Keeney (eds.), Bugs in the System: Redesigning the Pesticide Industry for Sustainable Agriculture, London: Earthscan Publications, pp. 17-49.

Ransom, E., L. Busch, and G. Middendorf (1998), 'Can cooperatives survive the privatization of biotechnology in agriculture', in Steven A. Wolf (ed.), Privatization of Information and Agricultural Industrialization, Boca Raton, New York: CRC Press, pp. 75-94.

Regal, P. (1999), 'A brief history of biotechnology risk debates and policies in the United States', Occasional Paper. Edmonds Institute, Edmonds, WA.

Rissler, J. and M. Mellon (1996), The Ecological Risks of Engineered Crops, Cambridge, MA: MIT Press.

Royal Society, The (1998, September), Genetically Modified Plants for Food Use, London: Carlton House Terrace.

Russell, K.A. (1991), 'Managing a biotechnology business', in V. Moses and R.E. Cape (eds.), London: Harwood Academic Press.

Ruttan, V.W. (1999), 'Biotechnology and agriculture: a skeptical perspective', Ag Bio Forum, 2(1): 54-60. (Retrieved 4 August 1999 from the world wide web http://www.agbioforum.missouri.edu).

Sandman, Peter (1999), 'Biotechnology: a risk communication perspective', Unpublished handout, Princeton, NJ: Consulting, Training and Research in Risk Communication.

Saxena, D., S. Flores, and G. Stutzky (1999), 'Insecticidal toxin in root exudates from Bt Corn', Nature, 402: 480.

Serageldin, I. (1999, 16 July), 'Biotechnology and food security in the 21st Century', Science, 285: 387-389.

Shapiro, R.B. (1999, April), 'How genetic engineering will save our planet', The Futurist, pp. 28-29.

Sigurdson, C. (2000, Summer), 'There's something fishy about a trojan horse gene', Perdue Agricultures Magazine, Perdue University, Layfayette, Indiana.

Snow, A., and P.M. Palma (1997), 'Commercialization of transgenic plants: potential ecological risks', BioScience, 47(2): 86-96.

US Congress, Office of Technology Assessment (OTA) (1993), 'Harmful non-indigenous species in the United States', OTA-F-566. Washington, DC: Government Printing Office.

USDA ERS (1999a), 'Genetically engineered crops for pest management', June 25 (updated October 27), US Dept. of Agriculture, Economic Research Service, Washington, DC. Available online at http://www.econ.ag.gov/whatsnew/ issues/biotech (verified 4 march 2000).

USDA ERS (1999b), 'Impacts of adopting genetically engineered crops in the US preliminary results', July 20, US Dept. of Agriculture, Economic Research Service, Washington, DC. Available online at http://www.econ.ag.gov/whatsnew/ issues/gmo/index.htm (verified March 4, 2000).

Waltrud, L.S. and R.J. Seidler (1998), 'Nontarget ecological effects of plant, microbial and chemical introductions to terrestrial systems', Soil Chemistry and Econosystem Health, Soil Science Society of America, Madison, WI (Special Publication no. 52: pp. 313-340).

Wargo, J. (1996), Our Children's Toxic Legacy: How Science and Law Fail to Protects Us from Pesticides, Haven, CO: Yale University Press.

Welsh, R. (1999), 'Genetically modified pest protected plants and sustainable 
agriculture', Paper Presented at American Bar Association Fall 1999 meeting, 7 October, San Diego, California.

Yanggen and T. Reardon (2001), 'Kudzu improved fallows in the Peruvian Amazon', in A. Angelsen and D. Kaimowitz (eds.), Agricultural Technologies and Tropical Deforestation, Wallingford: CAB International. 